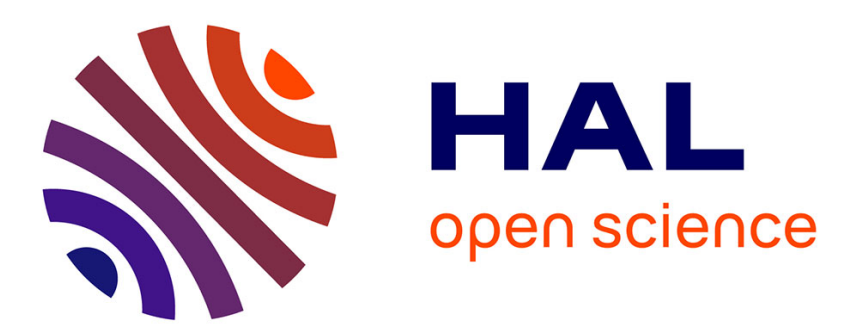

\title{
Reading action word affects the visual perception of biological motion
}

\author{
Christel Bidet-Ildei, Laurent Sparrow, Yann Coello
}

\section{To cite this version:}

Christel Bidet-Ildei, Laurent Sparrow, Yann Coello. Reading action word affects the visual perception of biological motion. Acta Psychologica, 2011, 137 (3), pp.330 - 334. 10.1016/j.actpsy.2011.04.001 . hal-01773532

\section{HAL Id: hal-01773532 \\ https://hal.science/hal-01773532}

Submitted on 17 Sep 2019

HAL is a multi-disciplinary open access archive for the deposit and dissemination of scientific research documents, whether they are published or not. The documents may come from teaching and research institutions in France or abroad, or from public or private research centers.
L'archive ouverte pluridisciplinaire HAL, est destinée au dépôt et à la diffusion de documents scientifiques de niveau recherche, publiés ou non, émanant des établissements d'enseignement et de recherche français ou étrangers, des laboratoires publics ou privés. 


\title{
Reading action word affects the visual perception of biological motion
}

\author{
Christel Bidet-Ildei ${ }^{1,2}$, Laurent Sparrow ${ }^{1}$, Yann Coello ${ }^{1}$
}

1 URECA (EA 1059), University of Lille-Nord de France,

2 CeRCA, UMR-CNRS 6234, University of Poitiers.

Corresponding author: Pr Yann Coello. Email: yann.coello@univ-lille3.fr

Running title: Biological motion perception

Keywords: Perception; Vision; Biological motion; Motor cognition, Language; Priming; Point-light display.

Mailing Address:



Tel: +33.3 .20 .41 .64 .46$

Fax: +33.3.20.41.60.32

Email: yann.coello@univ-lille3.fr 


\begin{abstract}
In the present study, we investigate whether reading an action-word can influence subsequent visual perception of biological motion. The participant's task was to perceptually judge whether a human action identifiable in the biological motion of a point-light display embedded in a high density mask was present or not in the visual sequence, which lasted for $633 \mathrm{~ms}$ on average. Prior to the judgement task, participants were exposed to an abstract verb or an action verb for $500 \mathrm{~ms}$, which was related to the human action according to a congruent or incongruent semantic relation. Data analysis showed that correct judgements were not affected by action verbs, whereas a facilitation effect on response time (48ms on average) was observed when a congruent action verb primed the judgement of biological movements. In relation with the existing literature, this finding suggests that the perception, the planning and the linguistic coding of motor action are subtended by common motor representations.
\end{abstract}




\section{Introduction}

In the last two decades, numerous studies in psychology and cognitive neurosciences have provided converging evidence supporting the idea that human movement observation and interpretation rely on the systems that are responsible for the performance of motor action (Keysers \& Perrett, 2004). Among the arguments, studies using positron emission tomography (PET) and functional magnetic resonance imagery (fMRI) have revealed overlapping brain activations within the motor areas while performing voluntary movements or simply observing similar movements performed by others (Hari et al., 1998; Nishitani \& Hari, 2000). The neural network reported included the mirror neuron system (inferior parietal and premotor cortices together with the motor and supplementary motor areas, Filimon, Nelson, Hagler, \& Sereno, 2007). Additional evidence came from the measure of magnetic (MEG) or electrical (EEG) brain activity (Cochin, Barthelemy, Roux, \& Martineau, 1999; Fadiga, Craighero, \& Olivier, 2005) with, for instance, a bilateral decrease of mu rhythm (8$13 \mathrm{hz}$ ) in sensory and motor brain areas during both the execution and observation of arm movements (Virji-Babul et al., 2008). In agreement with this, neuropsychological cases have revealed concurrent impairments of movement production and movement perception in patients showing motor disorders (Chary et al., 2004; Sirigu et al., 1995). Behavioural studies have also suggested that observing and performing an action rely on common processes. For instance, visual preferences for dynamical events are influenced by the spatio-temporal regularities known to constrain human actions (Bidet-Ildei, Méary, \& Orliaguet, 2006; Méary, Chary, Palluel-Germain, \& Orliaguet, 2005). Likewise, the perception of human movements improves following the learning of a new motor-skill congruent with the observed movement (Casile \& Giese, 2006) or even when simply executing the action before performing the perceptual task (Bidet-Ildei, Chauvin, \& Coello, 2010). Planning a goal-directed motor action seems even sufficient to improve the perceptual sensitivity to those events in the environment 
that are directly related to the motoric specification of this particular action (Bekkering \& Neggers, 2002; Fagioli, Ferlazzo, \& Hommel, 2007). Then, enriching our motor experience positively influences our capacities to perceive human actions (e.g., Bidet-Ildei et al., 2010; Calvo-Merino, Glaser, Grezes, Passingham, \& Haggard, 2005; Cross, Hamilton, \& Grafton, 2006; Loula, Prasad, Harber, \& Shiffrar, 2005). As a consequence, brain motor activations when passively observing a human action were reported to be broader when the observed performance fell within the observer's action repertoire, as for instance when professional dancer observed familiar dance movements (Calvo-Merino et al., 2005). Considered together, these findings strongly argue in favour of common motor representations for the observation and the production of voluntary actions (Hommel, Musseler, Aschersleben, \& Prinz, 2001; Prinz, 1997), though the underlying mechanism has been differently referred to either a resonance between motor and perceptual systems (Schütz-Bosbach \& Prinz, 2007), an internalized motor simulation during movement observation (Jeannerod, 2001), or the existence at the neuronal level of a mirror system between perception and action (Rizzolatti \& Craighero 2004).

Interaction between the visual and motor system was also highlighted in studies investigating the link between action production and action description with language (for a review, see Fischer \& Zwaan, 2008). Taking advantage of the somatotopic organisation of the motor cortex, Hauk, Johnsrude and Pülvermuller (2004) showed that when participants read verbs describing action performed with either the foot (kick), the hand (pick) or the face (lick), similar regions in the motor cortex were activated than during actual motor production. Additional evidence for the involvement of brain motor areas in action-words processing came from a PET study in which an increased activation of the premotor and motor cortex was observed when comparing motor noun and verbs to sensory noun and verbs (Vigliocco et al., 2006). On the basis of these data, action execution and action-word processing were 
considered as implying congruent neural activation in particular within the motor and premotor brain areas, in regions somatotopically related to the visual and semantic content of the stimulus (Aziz-Zadeh, Wilson, Rizzolatti, \& Iacoboni, 2006). Clinical reports have provided arguments in line with this interpretation by showing a close link between movement disorders (e.g., Parkinson's disease, Huttington's disease, progressive supranuclear palsy) or lesions in the motor brain areas and language impairments when processing actionwords (Bak, O'Donovan, Xuereb, Boniface, \& Hodges, 2001; Cotelli et al., 2006; Peran, Demonet, Pernet, \& Cardebat, 2004; Peran et al., 2003). Similarly, behavioural studies have provided arguments in favour of cross-talk between language and motor processes by showing, for instance, that language processing can automatically influence ongoing motor performance (Boulenger et al., 2006; Gentilucci, 2003; Glover \& Dixon, 2002; Nazir et al., 2008). Indeed, presenting an action-verb at the onset of a manual grasping task creates a rapid interference with movement execution affecting the initial acceleration of the hand (Boulenger et al., 2006). A recent study demonstrated that these effects cannot be attributed to the simple consequence of conscious processing of the word (Boulenger et al. 2008). In this respect, Boulenger et al. showed that presenting an action verb at a subliminal level during the preparation of a reaching movement modified the readiness potential recorded through the brain activity and the kinematic parameters of the motor response. These findings demonstrated then that action-words can automatically influence motor processes even when they are processed out of the field of consciousness. Considered together, these results support the notion of embodied semantics for actions based on shared neural representations for action production, action observation and verbal coding of action (Arbib, 2005, 2008; Aziz-Zadeh \& Damasio, 2008; Aziz-Zadeh \& Ivry, 2009; Fischer \& Zwaan, 2008).

On the basis of evidence for shared motor representations in action production and action observation on the one hand, and in action-related language and action production on 
the other hand, it is tempting to assume that action-related language and action observation should also rely on shared motor representations. In line with this assumption, several studies have revealed corresponding brain activations, in particular within a fronto-parietal network including the premotor cortex, when generating or reading an action-word, or mentally simulating or miming an action (Aziz-Zadeh et al. 2006; Péran et al., 2010). Likewise, Springer \& Prinz (2010) showed that action-word processing modulates the capacity to visually predict the outcome of a biological motion, suggesting a linkage between action simulation and action semantics. However, no behavioural study so far has specifically addressed the issue of the relationship between action-word processing and visual recognition of human actions. Taken for granted that the processing of action-word and the observation of human action rely on shared neural resources, one may assume that being exposed to actionword before perceiving a human action should influence the latter task. Testing this assumption represents the aim of the present study. Using a standard priming paradigm, we tested whether presenting a congruent instead of an incongruent action-verb or even an abstract-verb facilitated subsequent perception of a human action identifiable in the biological motion of a point-light display embedded in a high density mask.

\section{Method}

\section{Participants}

Eighteen right-handed healthy adults (9 females, 9 males) aged between 17 and 48 years (Mean age: 26.5years, standard deviation: 7.3years) participated in the experiment. None of them reported any sensory or motor deficits and all had normal or corrected-tonormal vision. This research was performed in agreement with the local ethical committee guidelines. They were naïve as to the purpose of the experiment and gave their informed consent prior to their inclusion in the study. 


\section{Stimuli and apparatus}

Participants sat comfortably in a dimly lit room facing a 17" CRT computer screen (Samsung 171S, spatial resolution: $1024 * 768$ pixels, sampling rate: $85 \mathrm{hz}$ ) placed on a horizontal table at a viewing distance of $50 \mathrm{~cm}$. Visual angle of the screen subtended at eyelevel was $26^{\circ}$ vertical $* 32^{\circ}$ horizontal. A computer keyboard was positioned on the table close to the body so that participants could easily provide their response during the experiment by pressing one of the keyboard keys. Stimuli were avi format animations showing biological motion of a point-light display representing the side-view of a man facing left while running (without translation), kicking or throwing a virtual ball respectively with the foot or the arm. Biological motion stimuli were composed of 13 points of light located on the main body joints (shoulders, elbows, wrists, hips, knees and ankles) and the head. We also used the same stimuli but in a scrambled condition, i.e. with each dot of the stimulus positioned at a random location (labelled respectively "scrambled running, kicking or throwing" stimuli). The animation sequences (biological or scrambled) were composed respectively of 24, 22 and 30 frames for the running, throwing or kicking movement condition or their scrambled equivalent. Each frame had a duration of $25 \mathrm{~ms}$, which resulted in a total duration of $550 \mathrm{~ms}, 600 \mathrm{~ms}$ and $750 \mathrm{~ms}$ respectively for the running, throwing and kicking stimuli. The duration of the stimuli corresponded to one complete cycle of each motor performance and were under the control of Matlab software using the coordinates provided by a point-light actions corpus freely accessible on the website: http://astro.temple.edu/ tshipley/ mocap/dotMovie.html (see Shipley \& Brumberg, 2004 for further details about the stimuli). Each point-light display consisted of white dots $\left(97 \mathrm{~cd} / \mathrm{m}^{2}, \varnothing: 0.65^{\circ}\right.$ of visual angle $)$ presented on a dark background $\left(0.14 \mathrm{~cd} / \mathrm{m}^{2}\right)$. Using the avifile Matlab routine (http://www.mathworks.com/), each sequence was transformed to an avi movie of $640 * 512$ 
pixels size and with a frame rate of 40 frames/s. The stimulus presented at the centre of the screen sustained a $4.9^{\circ}(\mathrm{V}) * 13.9^{\circ}(\mathrm{H})$ visual angle. Every stimulus was embedded in a mask made with 55 moving scrambled dots. Each dot in the mask appeared randomly on the screen and was animated with an angular motion and amplitude depending on the individual velocity vector of the point light display. Velocity vectors were sampled from one of the eleven points of the target stimuli when running, kicking or throwing respectively ( $\mathrm{x}$ and $\mathrm{y}$ coordinates being processed independently). Consequently, three animation sequences consisted in a human action (11 moving dots) embedded in 55 scrambled moving dots (running, kicking and throwing) and three animation sequences were composed of 66 scrambled moving dots (scrambled running, kicking and throwing ${ }^{1}$ ).

\section{Procedure and data analysis}

Before starting the experiment, participants were familiarised with examples of each biological motion presented without the mask, i.e. 3 successive presentations of the running, kicking and throwing stimuli. The name of the stimuli was provided in French language (courir, frapper, lancer). This procedure was used because some action-verbs, like "frapper", are ambiguous in French. The verb "frapper" can be used to describe the action of hitting, pushing or kicking. In the experimental session, the task for the participants was to perceptually judge the presence or absence of a human action (2AFC decision task) within the visual stimulus containing either a human action identifiable from the biological motion (running, kicking or throwing) or merely scrambled moving dots (scrambled running, kicking or throwing) embedded in a dynamical mask of 55 dots (never seen before). Stimuli presentation and manual responses registration were under the control of E-prime software (version 2.0, http://www.pstnet.com/).

\footnotetext{
${ }^{1}$ The stimuli used in the experiment are available at the following internet address: https://bv.univ-poitiers.fr/access/content/user/cildei/stimuli/
} 
Responses were recorded by clicking on the letter "A" (response no) or "P" (response yes) of the computer keyboard respectively with the left and the right hand for half of the participants, and respectively with the right and the left hand for the other half. Before presenting the biological motion stimulus in the experimental session, participants were exposed for $500 \mathrm{~ms}$ to a French word, which was either an action verb: "courir" (run), "lancer" (throw), "frapper" (kick) or a non-action verb: "penser" (think). The verb was displayed at the centre of the screen using a 26 point Courier New font and was related to the following biological motion according to a congruent, incongruent or neutral semantic relationship. All of these verbs were high-frequency verbs in French (frequency was equal or superior to 26.08 occurrences per 100 million, New, Pallier, Ferrand, \& Matos, 2001). This presentation time, was chosen because according to the literature, it corresponds to the time necessary to read and access to the meaning of a visual word (for a review, see Kutas \& Federmeier, 2009). Before presenting the verb, a fixation cross appeared at the centre of the screen for $500 \mathrm{~ms}$ and played as a warning signal indicating the beginning of a new trial (Figure 1). Each stimulus (biological or scrambled motion) was associated with the various verbs resulting in a session of 192 trials ( 8 repetitions $* 4$ words $* 6$ stimuli) with a total duration of about $20 \mathrm{~min}$. 


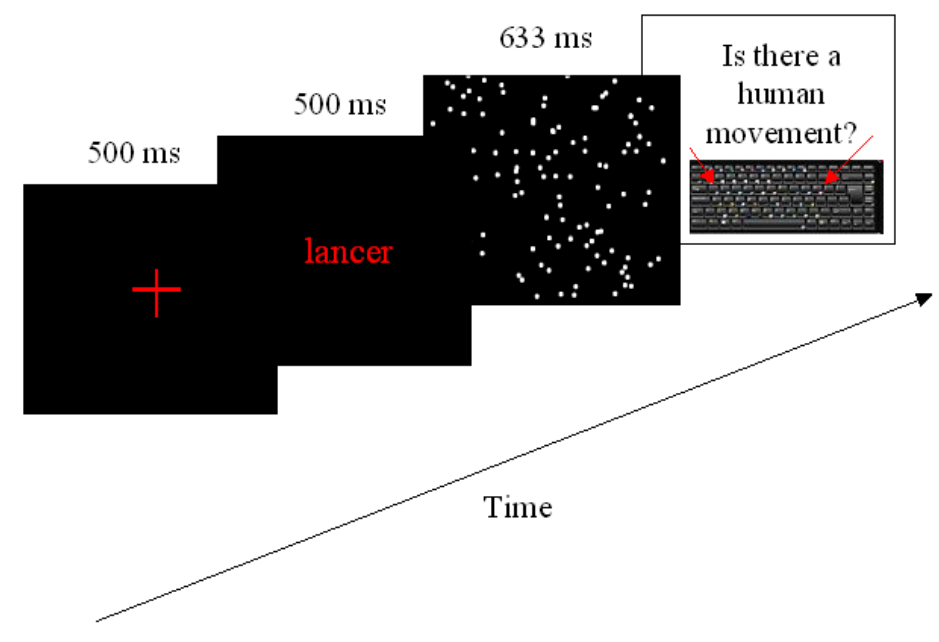

Figure 1. A) Experimental procedure used in the experiment. A central fixation cross was presented for 500ms, then a word (courir-running, lancer-throwing, frapper-kicking, penserthinking) was displayed for 500ms before a biological or a scrambled stimulus was presented embedded in a dynamical mask for $633 \mathrm{~ms}$ on average. Participants responded whether they perceived or not a human action in the stimulus by pressing the corresponding key (yes-no) on the computer keyboard. B) Static representation of the different point-light animation used in the experiment. Upper panel represents the biological stimuli with red dots representing the target dots and white dots the mask (in the experimental display all dots were white). Lower panel represents scrambled stimuli.

Participants' response accuracy (correct identifications) and response time (time to provide the response from the onset of the stimulus presentation) were analysed according to the stimulus (biological or scrambled), the priming information (congruent, incongruent or 
neutral) and the action (running, throwing or kicking action). Statistical analysis was performed using a three-way analysis of variance (ANOVA) with all variables considered as within-subjects factors. In case the sphericity assumption was violated (i.e. Epsilon smaller than 1), Huyn-Feldt adjustments of the p-values were reported. Local comparisons were performed using t-test with Bonferroni correction for multiple comparisons. Effect-sizes were computed using eta-square estimates.

\section{Results}

Response accuracy

Statistical analysis (see Fig 2A) revealed no significant effect of the stimulus $(\mathrm{F}(1,17)=1.67, \mathrm{p}=0.21)$, the action $(\mathrm{F}(2,34)=2.55, \mathrm{p}=0.09)$ and the priming information $(\mathrm{F}(2,34)=0.42, \mathrm{p}=0.66)$ No interaction appeared between these different factors. Thus, whatever prior semantic information, participants showed a high rate of successful performance $($ Mean $=93 \%)$ when assessing the presence or not of a human action embedded in a dynamical mask.

\section{Response time}

Statistical analysis (see Fig 2B) revealed a principal effect of both the stimulus $\left(F(1,17)=17.5 ; \mathrm{p}<0.001, \eta^{2}=0.94\right)$ and the action $\left(F(2,34)=9.89 ; \mathrm{p}<0.001, \eta^{2}=0.90\right)$. Response time was higher for the scrambled (Mean=880 ms, SD=254 ms) than the biological stimuli (Mean=798 ms, SD=210 ms). Moreover, response time was higher for kicking (Mean=900 ms $\mathrm{SD}=257 \mathrm{~ms}$ ) than running (Mean= $779 \mathrm{~ms}, \mathrm{SD}=241 \mathrm{~ms}$ ) and throwing (Mean=840 ms, $\mathrm{SD}=217 \mathrm{~ms}, \mathrm{t}(17)=1.92$ and $\mathrm{t}(17)=2.36$, both, $\mathrm{p}<0.05)$. Throwing response time was also higher than running $(\mathrm{t}(17)=5.11, \mathrm{p}<0.001)$. However this difference disappeared when we removed the difference of time presentation between the stimuli $(F(2,34)=1.19 ; \mathrm{p}=0.31)$. 
Interestingly, we found also a significant interaction between the stimulus and the priming information $\left(\mathrm{F}(2,34)=5.25 ; \mathrm{p}=0.01, \quad \eta^{2}=0.84\right)$. When perceptual judgements concerned biological stimuli, post-hoc analysis indicates that the congruent priming condition (Mean: $765 \mathrm{~ms}, \mathrm{SD}=207 \mathrm{~ms}$ ) produced a facilitation effect reducing the time required to provide the response in comparison to the incongruent (Mean: $808 \mathrm{~ms}, \mathrm{SD}=207 \mathrm{~ms}$ ) and the neutral (Mean: $820 \mathrm{~ms}, \mathrm{SD}=227 \mathrm{~ms}$ ) priming conditions $(\mathrm{t}(17)=3.27$ and $\mathrm{t}(17)=2.48$; respectively, both $\mathrm{p}<0.05)$, whereas these two last conditions did not differ $(\mathrm{t}(17)=0.42$, $\mathrm{p}=0.83$ ). When perceptual judgements concerned scrambled stimuli, post-hoc analysis revealed no effect of priming information. Other interactions were not significant.
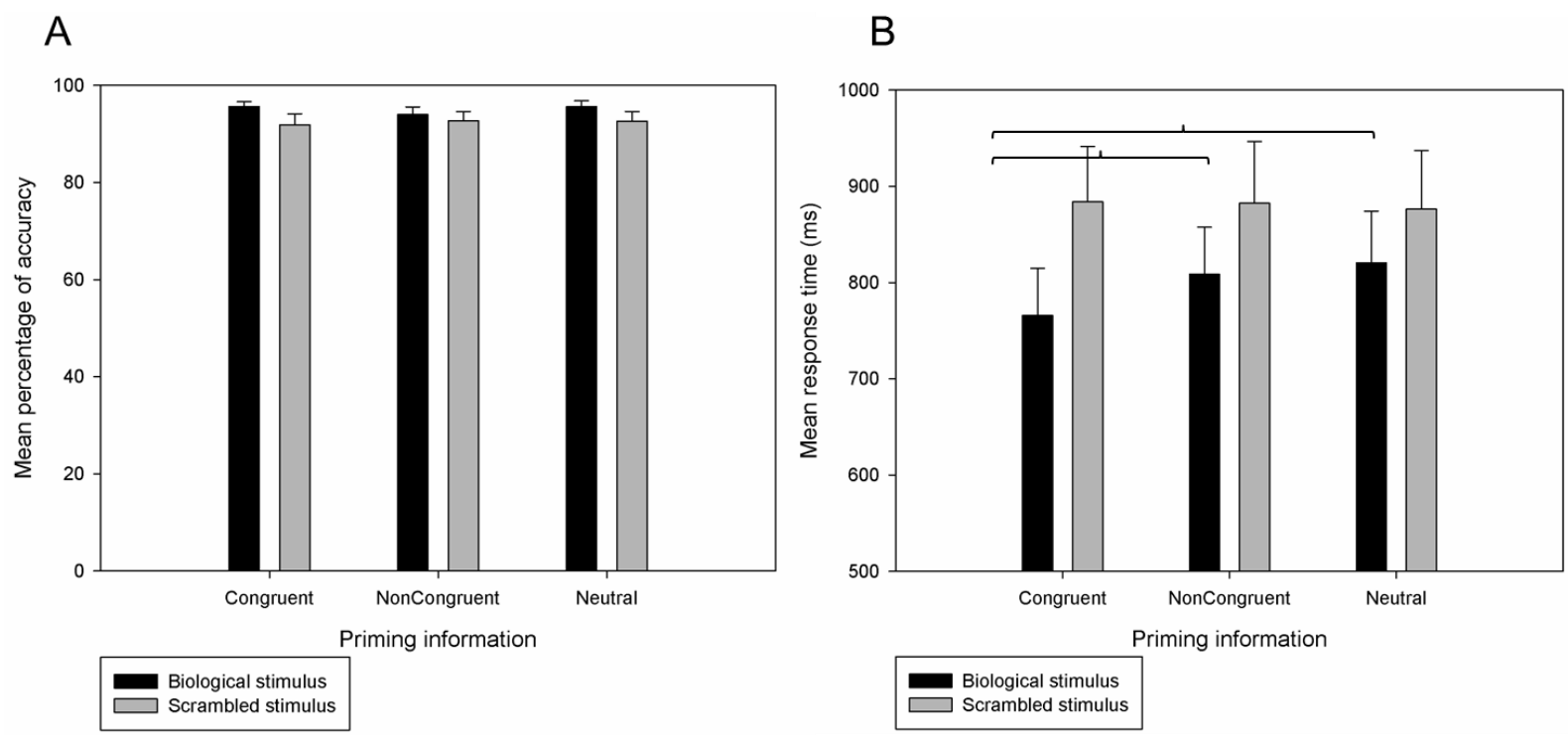

Figure 2. Mean and standard error for accuracy (A) and response time (B) according to the stimulus (biological or scrambled stimulus) and the priming information (congruent, incongruent or neutral). 


\section{Discussion}

The aim of the present study was to test the effect of reading an action-verb before perceptually judging whether a human action identifiable in the biological motion of a pointlight display embedded in a high density mask was present or not. The main finding was that reading a congruent action-verb facilitated subsequent perception of human-, but not scrambled-action. Indeed, a decrease of $48 \mathrm{~ms}$ in response time was observed when a congruent action verb was presented before judging whether a human action was present or not, compared to the control condition (neutral verb). This facilitation effect was not observed when presenting an incongruent action-verb before the perceptual judgement task. The same effect was obtained whatever the action presented (running, throwing or kicking). This suggests that the effect observed was independent of the effector used to respond (i.e., upper limbs), which could be explained by the fact that the task consisted in detecting movements implicating the whole body (running, throwing and kicking), and not only the arms. However, this effect concerned only response time and not response accuracy, which reached $93 \%$ on average whatever the priming condition. This lack of effect on correct judgements could be explained by the easiness of the perceptual task since the presence of a human action provided a structured biological motion rendering the decision process quite straightforward.

The present study provides then new evidence for an influence of prior action-related information on the perception of human movements. It extends previous works that have investigated the relation between language comprehension and action prediction (e.g. Springer \& Prinz, 2010) by showing that action-words can automatically improve the recognition of human movements, even when the perceptual task does not explicitly require action simulation. Indeed, contrary to motor outcome anticipatory tasks (i.e., Chaminade, Meary, Orliaguet, \& Decety, 2001), the recognition or detection of a biological movement does not necessary require the contribution of motor-related information (e.g., Pavlova, 
Staudt, Sokolov, Birbaumer, \& Krageloh-Mann, 2003). However, it is well acknowledged that the perception of biological movements is facilitated when participants judge movements for which they have a particular expertise (Calvo-Merino et al., 2005, Casile \& Giese 2006), or they have executed or observed just before the perceptual task (Bidet-Ildei et al., 2010). Here, we completed these findings by showing that reading an action-verb can also facilitate the visual perception of a human movement, suggesting that the two tasks share common processes.

In all, these data strongly suggest that prior motor-related information can constrain and even determine what is later perceived by the visual system (Schütz-Bosbach \& Prinz, 2007). Consequently, one may speculate that the representation activated when reading an action-verb, or when producing or observing a human action, implies common neural resources. Indeed, the facilitation effect on response time when presenting a congruent actionverb before performing the perceptual judgement task could be accounted for by the fact that the brain structures involved in biological motion perception are primed by the linguistic stimulus (Aziz-Zadeh et al., 2006). In agreement with this, the facilitation effect was observed when participants were in the presence of a biological movement, but not when participants were in the presence of only the dynamical mask. Thus, the faster response time in the congruent condition was not the result of the perception of the dynamical properties of the whole visual stimulation, but the result of an embodied perception of the biological stimuli, relying on action-dependent visual processes overlapping with those usually involved in action words reading. Consequently, in the continuation of previous studies which have underlined that prior execution or observation of an action improve later perception of congruent human actions (e.g. Bidet-Ildei et al., 2010), the present study showed that similar effect can be obtained with prior exposition to action-verb. Various explanations have been considered in the past to account for interactions between language and action, including the 
existence of common processing involved in production of action and comprehension of action-related words (i.e., Pulvermuller, 2005), the intervention of a motor resonance system during semantic processes (Taylor \& Zwaan, 2008), or the intervention of a "mirror system" in processing implying action i.e., execution, observation, and conceptualisation (e.g., Chen \& Yuan, 2008). Though it was not our aim to unravel these different theories, our findings support the general view that action observation, action production and action-word comprehension rely on shared motor representations.

In conclusion, although some issues remains to be properly addressed (as for example the actual role of motor imagery in language processing, Kemmerer \& Gonzalez-Castillo, 2008; Willems \& Hagoort, 2007, and whether activating motor representations in language perception is determinant for accessing to word meaning, Jeannerod, 2006), the present study clearly provides behavioural evidence that the recognition of a human action can be facilitated by prior exposure to action-related language. 


\section{References}

Arbib, M. A. (2005). From monkey-like action recognition to human language: an evolutionary framework for neurolinguistics. Behav Brain Sci, 28(2), 105-124; discussion 125-167.

Arbib, M. A. (2008). From grasp to language: Embodied concepts and the challenge of abstraction. J Physiol Paris, 102(1-3), 4-20.

Aziz-Zadeh, L., \& Damasio, A. (2008). Embodied semantics for actions: findings from functional brain imaging. J Physiol Paris, 102(1-3), 35-39.

Aziz-Zadeh, L., \& Ivry, R. B. (2009). The human mirror neuron system and embodied representations. Adv Exp Med Biol, 629, 355-376.

Aziz-Zadeh, L., Wilson, S. M., Rizzolatti, G., \& Iacoboni, M. (2006). Congruent embodied representations for visually presented actions and linguistic phrases describing actions. Curr Biol, 16(18), 1818-1823.

Bak, T. H., O'Donovan, D. G., Xuereb, J. H., Boniface, S., \& Hodges, J. R. (2001). Selective impairment of verb processing associated with pathological changes in Brodmann areas 44 and 45 in the motor neurone disease-dementia-aphasia syndrome. Brain, 124(Pt 1), 103-120.

Bekkering, H., \& Neggers, S. F. (2002). Visual search is modulated by action intentions. Psychol Sci, 13(4), 370-374.

Bidet-Ildei, C., Chauvin, A., \& Coello, Y. (2010). Observing or producing a motor action improves later perception of biological motion: Evidence for a gender effect. Acta Psychologica (Amst), 134 (2), 215-224.

Bidet-Ildei, C., Méary, D., \& Orliaguet, J.-P. (2006). Visual perception of elliptic movements in 7-to-11 year old children: Evidence of motor-perceptual interactions. Current psychology Letters, 2(19). 
Boulenger, V., Roy, A. C., Paulignan, Y., Deprez, V., Jeannerod, M., \& Nazir, T. A. (2006). Cross-talk between language processes and overt motor behavior in the first $200 \mathrm{msec}$ of processing. J Cogn Neurosci, 18(10), 1607-1615.

Calvo-Merino, B., Glaser, D. E., Grezes, J., Passingham, R. E., \& Haggard, P. (2005). Action observation and acquired motor skills: an FMRI study with expert dancers. Cerebral Cortex, 15(8), 1243-1249.

Casile, A., \& Giese, M. A. (2006). Nonvisual motor training influences biological motion perception. Current Biology, 16(1), 69-74.

Chaminade, T., Meary, D., Orliaguet, J. P., \& Decety, J. (2001). Is perceptual anticipation a motor simulation? A PET study. Neuroreport, 12(17), 3669-3674.

Chary, C., Meary, D., Orliaguet, J. P., David, D., Moreaud, O., \& Kandel, S. (2004). Influence of motor disorders on the visual perception of human movements in a case of peripheral dysgraphia. Neurocase, 10(3), 223-232.

Chen, W., \& Yuan, T. F. (2008). Mirror neuron system as the joint from action to language. Neurosci Bull, 24(4), 259-264.

Cochin, S., Barthelemy, C., Roux, S., \& Martineau, J. (1999). Observation and execution of movement: similarities demonstrated by quantified electroencephalography. Eur $J$ Neurosci, 11(5), 1839-1842.

Cotelli, M., Borroni, B., Manenti, R., Alberici, A., Calabria, M., Agosti, C., et al. (2006). Action and object naming in frontotemporal dementia, progressive supranuclear palsy, and corticobasal degeneration. Neuropsychology, 20(5), 558-565.

Cross, E. S., Hamilton, A. F., \& Grafton, S. T. (2006). Building a motor simulation de novo: observation of dance by dancers. Neuroimage, 31(3), 1257-1267.

Fadiga, L., Craighero, L., \& Olivier, E. (2005). Human motor cortex excitability during the perception of others' action. Curr Opin Neurobiol, 15(2), 213-218. 
Fagioli, S., Ferlazzo, F., \& Hommel, B. (2007). Controlling attention through action: observing actions primes action-related stimulus dimensions. Neuropsychologia, $45(14), 3351-3355$

Filimon, F., Nelson, J. D., Hagler, D. J., \& Sereno, M. I. (2007). Human cortical representations for reaching: mirror neurons for execution, observation, and imagery. Neuroimage, 37(4), 1315-1328.

Fischer, M. H., \& Zwaan, R. A. (2008). Embodied language: a review of the role of the motor system in language comprehension. QJ Exp Psychol (Colchester), 61(6), 825-850.

Gentilucci, M. (2003). Object motor representation and language. Exp Brain Res, 153(2), 260265.

Glover, S., \& Dixon, P. (2002). Semantics affect the planning but not control of grasping. Exp Brain Res, 146(3), 383-387.

Hari, R., Forss, N., Avikainen, S., Kirveskari, E., Salenius, S., \& Rizzolatti, G. (1998). Activation of human primary motor cortex during action observation: a neuromagnetic study. Proceedings of the National Academy of Sciences U S A, 95(25), 15061-15065.

Hauk, O., Johnsrude, I., \& Pulvermuller, F. (2004). Somatotopic representation of action words in human motor and premotor cortex. Neuron, 41(2), 301-307.

Hommel, B., Musseler, J., Aschersleben, G., \& Prinz, W. (2001). The Theory of Event Coding (TEC): a framework for perception and action planning. Behav Brain Sci, 24(5), 849-878; discussion 878-937.

Jeannerod, M. (2001). Neural simulation of action: a unifying mechanism for motor cognition. Neuroimage, 14(1 Pt 2), S103-109.

Jeannerod, M. (2006). Motor Cognition: What Actions Tell to the Self. Oxford: Oxford University Press. 
Kemmerer, D., \& Gonzalez-Castillo, J. (2008). The Two-Level Theory of verb meaning: An approach to integrating the semantics of action with the mirror neuron system. Brain Lang.

Keysers, C., \& Perrett, D. I. (2004). Demystifying social cognition: a Hebbian perspective. Trends Cogn Sci, 8(11), 501-507.

Kutas, M., \& Federmeier, K. D. (2009). Thirty Years and Counting: Finding Meaning in the N400 Component of the Event-Related Brain Potential (ERP). Annu Rev Psychol.

Loula, F., Prasad, S., Harber, K., \& Shiffrar, M. (2005). Recognizing people from their movement. Journal of Experimental Psychology Human Perception and Performance, $31(1), 210-220$.

Méary, D., Chary, C., Palluel-Germain, R., \& Orliaguet, J. P. (2005). Visual perception of writing and pointing movements. Perception, 34(9), 1061-1067.

Nazir, T. A., Boulenger, V., Roy, A., Silber, B., Jeannerod, M., \& Paulignan, Y. (2008). Language-induced motor perturbations during the execution of a reaching movement. Q J Exp Psychol (Colchester), 61(6), 933-943.

New, B., Pallier, C., Ferrand, L., \& Matos, R. (2001). Une base de données lexicales du français contemporain sur internet: LEXIQUE. L'Année psychologique, 101, 447-462. http://www.lexique.org.

Nishitani, N., \& Hari, R. (2000). Temporal dynamics of cortical representation for action. Proceedings of the National Academy of Sciences US A, 97(2), 913-918.

Pavlova, M., Staudt, M., Sokolov, A., Birbaumer, N., \& Krageloh-Mann, I. (2003). Perception and production of biological movement in patients with early periventricular brain lesions. Brain, 126(Pt 3), 692-701. 
Peran, P., Demonet, J. F., Cherubini, A., Carbebat, D., Caltagirone, C., \& Sabatini, U. (2010). Mental representations of action: the neural correlates of the verbal and motor components. Brain Res, 1328, 89-103.

Peran, P., Demonet, J. F., Pernet, C., \& Cardebat, D. (2004). Verb and noun generation tasks in Huntington's disease. Mov Disord, 19(5), 565-571.

Peran, P., Rascol, O., Demonet, J. F., Celsis, P., Nespoulous, J. L., Dubois, B., et al. (2003). Deficit of verb generation in nondemented patients with Parkinson's disease. Mov Disord, 18(2), 150-156.

Prinz, W. (1997). Perception and action planning. European Journal of Cognitive Psychology, $9(2), 129-154$.

Pulvermuller, F. (2005). Brain mechanisms linking language and action. Nat Rev Neurosci, $6(7), 576-582$.

Rizzolatti, G. and Craighero, L. (2004). The mirror-neuron system. Annual Review of Neuroscience, 27, 169-192.

Schütz-Bosbach, S., \& Prinz, W. (2007). Perceptual resonance: action-induced modulation of perception. Trends in Cognitive Sciences, 11(8), 349-355.

Shipley, T. F., \& Brumberg, J. S. (2004). Markerless motion-capture for point-light displays.

Sirigu, A., Cohen, L., Duhamel, J. R., Pillon, B., Dubois, B., \& Agid, Y. (1995). A selective impairment of hand posture for object utilization in apraxia. Cortex, 31(1), 41-55.

Springer, A., \& Prinz, W. (2010). Action semantics modulate action prediction. $Q J$ Exp Psychol (Colchester), 1-18.

Taylor, L. J., \& Zwaan, R. A. (2008). Motor resonance and linguistic focus. Q J Exp Psychol (Colchester), 61(6), 896-904. 
Vigliocco, G., Warren, J., Siri, S., Arciuli, J., Scott, S., \& Wise, R. (2006). The role of semantics and grammatical class in the neural representation of words. Cereb Cortex, 16(12), 1790-1796.

Virji-Babul, N., Moiseev, A., Cheung, T., Weeks, D., Cheyne, D., \& Ribary, U. (2008). Changes in mu rhythm during action observation and execution in adults with Down syndrome: implications for action representation. Neurosci Lett, 436(2), 177-180.

Willems, R. M., \& Hagoort, P. (2007). Neural evidence for the interplay between language, gesture, and action: a review. Brain Lang, 101(3), 278-289. 
